\title{
DESINFECÇÃO DO INSTRUIMENTAL ENDODÔNTICO COM STERYLDERME, GERMEKIL, CETAVLON, ZEFIROL E DENIGÉS
}

\section{SINOPSE}

Testada a ação desinfetante de vários agentes de uso odontológico sôbre culturas conhecidas da bacterioteca e de canais radiculares.

\section{1 - INTRODUCX̃O}

Mau grado os trabalhos de que tem sido objeto em noso país o problema da esterilização a frio do instrumental de uso endodôntico, ainda continua a preocupar a classe odontológica.

Trabalha-se, investiga-se e experimenta-se, no sentido de se obter um produto que satisfaça sob todos os pontos de vista.

Várias fórmulas e preparados têm sido preconizadas. Revisando alguns trabalhos a respeito encontramos a seguinte situação:

MADUREIRA ${ }^{18}, 1960$, «aconselha a classe odontológica a usar com segurança o bromêto de cetiltrimeti-

\section{Paulo Monteiro Freitas}

Professor Assistente do Departamento de Odontologia Preventiva e Social.

lamonio na diluição de $0,5 \%$ para a esterilização completa de todos os instrumentos de endodontia (brocas, extirpa-nervos, alargadores, limas etc.) imergindo-os em apenas 15 segundos na solução proposta.»

MADUREIRA ${ }^{16} 1960$, «chegamos à conclusão de que, numa diluição de $0,5 \%$ do bromêto citado quando em contato com culturas de B. subtilis e o bacilo do carbúnculo hemático, nos tempos de 10-15-20-25 e 30 segundos, conseguimos destruir seus esporos nos testes tomados após 15 segundos para o B. subtilis e 10 para o bacilo do carbúnculo hemático.»

PORTELADA 22 , 1960, testou o líquido de Badan frente a uma amostra Hopkins de Salmonella typhosa e concluiu que o mesmo «não tem ação esterilizante alguma. A pesquisa bibliográfica veio demonstrar que o líquido, em sua fórmula original, era feito com cianeto de mercúrio e não com cianeto de potássio como vem sendo largamente usado. O li- 
quido de Denigés mostrou efetivamente uma ação esterilizante mesmo quando a ação se fêz por 5 minutos».

TOVO ${ }^{26}$, 1962, «testou o efeito do líquido de Denigés, defendido por Badan frente um «pool» de bactérias e o resultado foi que após 24 horas não havia crescimento ou seja, negativo para todos os tempos de ação do líquido, o que permitiu qualificar o preparado de 'ótimo»، Em outra experiência, o mesmo autor, testou nos mesmos moldes o bromêto de cetiltrimetilamônio (Cetavlon) ou seja frente ao mesmo coquetel de microrganismos e verificou que o mesmo «não produzia nenhuma ação impediente no seu crescimento».

LIMA E TABACOF 12 , 1964, «concluíram que o líquido de Denigés, fórmula de Badan. não tem poder esterilizante mas que o Denigés original dá ótimo resultado a partir de 10 minutos de contato». Testando o bromêto de cetiltrimetilamônio (Cetavlon) a $0,5 \%$ concluíram que «com um contato acima de 10 minutos é um bom agente desinfetante. Os resultados de Tovo não foram confirmados quanto à ação do líquido de Denigés frente ao coquetel pois houve crescimento desde 1 a $30 \mathrm{mi}-$ nutos».

MARCOS PRODUTOS QUŶMICOS ${ }^{20}$, em seus dados técnicos sôbre o princípio ativo do Sterylderme aconselha o uso do mesmo como germicida e esterilizante do material cirúrgico.

COOLIDGE E KESEL ${ }^{6}$, 1956-1957, afirmam que o «Zefiran é um sal quaternário do amônio amarelo e solúvel. É um antisséptico não irritante e efetivo, útil em solução $1 / 1000$ para a desinfecção profilática da pele intata. Para o seu emprêgo na membrana mucosa é indicada uma solução mais diluída. $\tilde{E}$ útil para a esterilização de limas e outros instrumentos para a prática endodôntica.

O CONSELHO DE TERAPÊUTICA DA ASOCIAÇÃO DENTAL AMERI$\mathrm{CANA}^{1}, 1962$, examinando a solução aquosa de cloreto de benzalcônio (Zefirol) concluiu que o mesmo «possui atividades bacteriostática e bactericida contra microrganismos não esporulados com exceção do $\mathrm{M}$. tuberculosis».

$O$ fato que realmente chamou-nos a atencão foi a ausência em todos os trabalhos citados, de referência ao estreptococo, microrganismo que comprovadamente está presente e em predomínio nos canais radiculares de cultivos positivos.

SIEBERTH ${ }^{10}, 1900$, já dizia que «pulpite é essencialmente devido a uma invasão estreptocócica.

MORSE E YATES ${ }^{21}$, 1941, verificaram ue «no canal radicular o microrganismo mais freqüentemente achado foi o estreptoco gama, seguido do estafilococo albus, estreptococo viridans e estafilococo aureus. Também encontrou estreptococo hemolítico.»

FILGUEIRAS E MELLO ${ }^{10}, 1947$, «em trabalhos realizados de 1940 a 1944 em 376 casos de infecção pulpar, encontraram a incidência de estreptococos (várias raças e tipos) na percentagem de $84 \%$, isolados ou associados a outras espécies patogênicas ou saprófitas.

FILGUEIRAS E MELLO ${ }^{9}, 1955$, dizem «os preparados à base de fenóis e cresois gozam de grande curso. A 
maioria dêstes preparados de procedência alemã, desapareceu do comércio durante a segunda guerra mundial e não foi reintroduzida após a terminação do conflito. Desde êste tempo vimos empregando uma forma preconizada por Badan de fácil preparo e resultados satisfatórios:
Cianeto de potássio

Borato de sódio

Cromato de potássio

Água destilada
$1,0 \mathrm{~g}$

$2,5 \mathrm{~g}$

$0,5 \mathrm{~g}$

$1000 \mathrm{ml}$
SOMMER, OSTRANDER E CROWLEY $^{25}$, 1958, concluíram que «os estreptococos são os microrganismo que se isolam com mais freqüência nos canais radiculares. Em $82 \%$ de uma série de 357 cultivos continham estreptococos dos quais $53 \%$ estavam presentes em culturas puras.

WINKLER E VON AMEROGEN 28 , 1959, trabalharam com 4.186 culturas de canais radiculares sendo que o total de 1.141 culturas positivas verificaram a preponderância dos estreptococos.

FILGUEIRAS, BEVILACQUA E MELLO ${ }^{8}, 1962$, publicaram: «usamos há muito tempo a fórmula divulgada por Badan:

Cianeto de potássio $1,0 \mathrm{~g}$ Borato de sódio $2,5 \mathrm{~g}$ Cromato neutro de potássio $0,5 \mathrm{~g}$ Água destilada $1000 \mathrm{ml}$

Esta solução é de fácil preparação, fornece resultados muito satisfatórios e conserva-se bem por longo espaço de tempo. Atualmente usase com sucesso para o mesmo fim soluções detergentes catiônicas como o Zefirol que é o cloreto de acetildimetil-benzil-amônio.»
GROSSMAN ${ }^{11}$, 1956, diz que «de um modo geral os compostos quaternários de amônio são eficazes contra microrganismo Gram-positivos e Gram-negativos, sendo menos eficazes contra fungos e leveduras e não são considerados como bons esporulicidas. Dêstes compostos o melhor conhecido é provàvelmente o cloreto de alquil-dimetil-benzil-amônio (Zephiran), relacionado na $13^{a}$ edição da farmacopeia dos EE.UU. com o nome de cloreto de benzalcônio».

CAUDURO $^{5}$, 1964, «aconselha o uso de duas soluções químicas para a esterilização dos instrumentos endodônticos:

$1^{\text {q }}$ Fórmula:

Cetavlon concentrado a $20 \% 2,5 \mathrm{ml}$ Ferrugol $20 \%$ $1,0 \mathrm{ml}$

Água destilada $96,5 \mathrm{ml}$

O instrumento deverá permanecer 15 segundos na solução.

$2^{q}$ Fórmula:

Líquido de Denigés

Cianeto de mercúrio $1 \mathrm{~g}$

Borato de sódio $5 \mathrm{~g}$

Cromato de potássio $\quad 0,5 \mathrm{~g}$

$\mathrm{H}_{2} \mathrm{O}$ destilada $1000 \mathrm{~m} 1$

A fórmula de Badan que é de fácil preparação, de resultados satisfatórios, conserva-se por longo espaço de tempo, porém, é aconselhável substituí-la cada 15 dias, é a seguinte:

Cianeto de potássio $1 \mathrm{~g}$

Borato de sódio $2,5 \mathrm{~g}$

Cromato neutro de potássio $0,5 \mathrm{~g}$ Água destilada $\quad 1000 \mathrm{ml} \gg$ 
O LABORATÓRIO DARROW ${ }^{15}$, 1955, aconselha o uso do Germekil para instrumental pois «é esterilizante em 30 minutos e desinfetante em 5 minutos».

O INSTITUTO TECNOLóGICO DO ESTADO DO RIO GRANDE DO SUL ${ }^{13}$, 1964, apresentou um relatório à Química Bayer S.A., informando «o desinfetante Zefirol numa diluição de $1 / 25.000$ inibiu o crescimento de uma cultura de Staphilococcus aureus em 5 minutos».

Face aos dados fornecidos nos trabalhos, anteriormente relatados, propusemo-nos na presente investigação, utilizando-nos de técnicas similares às usadas pelos vários autores, a testar comparativamente um grupo de agentes químicos antibacterianos, de uso médico-odontológico, contra microrganismos isolados bem como um coquetel de bactérias da bacterioteca do Setor de Microbiologia da F.O.U.F.R.G.S., e, contra culturas de condutos radiculares infectados bem como contra estreptococos isolados destas culturas.

\section{2 - MATERIAL E MÉTODOS}

2.1. Agentes Esterilizantes Testados:

2.1.1. Cloreto de alquil-dimetilbenzil-amônio

Nome Comercial:

Zefirol13

Cloreto de alquil-

dimetil-benzil-amônio

$5 \mathrm{ml}$

Agua destilada

$100 \mathrm{ml}$
2.1.2. Cloreto de Benzildimetil

2 (2. (p. 1.1.3.3. tetrametil butil fenoxi) etoti etil) amônio

Nome Comercial:

Sterylderme ${ }^{20}$

Sterylderme concentrado $\quad 100 \mathrm{ml}$

Alcool $\quad 1000 \mathrm{ml}$

2.1.3. Brometo de cetiltrimetilamônio

Nome Comercial:

Cetavlon 18

Cetavion concentrado (20\%) $5 \mathrm{ml}$

Ferrugol ss White

$10 \mathrm{ml}$

Água comum $985 \mathrm{ml}$

2.1.4. Cloreto de benzil-dimetil (2 (2. (p. 1.1.3.3. tetrametil-butil-fenoxi) etoxi etil) amônio metanal iso aril-alquil-polietoxi-etanol

Nome Comercial :

Germekil 15

Germekil concentra-

do

$100 \mathrm{ml}$

Álcool $\quad 1000 \mathrm{ml}$

2.1.5. Liquido de Denigés, Fórmula Original ${ }^{24}$

Cianeto de mercúrio $1,0 \mathrm{~g}$

Borato de sódio $2,5 \mathrm{~g}$ Cromato de potássio $0,5 \mathrm{~g}$ Agua destilada q.b.p.

$1000 \mathrm{ml}$ 
2.1.6. Líquido de Denigés, Fórmula modificada por Pio Portellada22

Cianeto de mercúrio $1,0 \mathrm{~g}$ Borato de sódio $5,0 \mathrm{~g}$ Cromato de potássio $0,5 \mathrm{~g}$ Água destilada q.b.p. $1000 \mathrm{ml}$

2.2. Microrganismos testados:

$$
\begin{aligned}
& 1 \text { - B. subtilis - Origem A.T. } \\
& \text { C.C. } 6633 \\
& 2 \text { - St. aureus - Origem A.T. } \\
& \text { C.C. } 209 \mathrm{P} \\
& 3 \text { - K. pneumoniae - Origem } \\
& \text { I.O.C. } 1062 \\
& 4 \text { - S. typhosa - Hopkins - } \\
& \text { Origem I.O.C. } \quad 1087 \\
& 5 \text { - P. vulgaris - Origem A. } \\
& \text { T.C.C. } \quad 9920 \\
& 6 \text { - S. marcescens - Origem } \\
& \text { Bacterioteca da FOPA } \\
& 7 \text { - E. coli - Origem A.T.C.C. } \\
& 9637
\end{aligned}
$$

2.2.2. Microrganismos colhidos de canais radiculares de dentes em tratamento endodôntico e que cresceram em caldo infuso coração de boi14 (ceta- vlon e Liquido de Denigés) e Bacto Brain $\mathrm{He}-$ art Infusion (Sterylderme e Zefirol).

\subsection{Métodos.}
2.3.1. Método com microrga- nismos isolados (Qua- dro I)

2.3.1.1. Cultivar c a d a um dos microrg a n is mos da bacterioteca, na estufa a $37^{\circ} \mathrm{C}$. durante 24 horas. Nos testes realizados $\mathrm{com}$ - Cetavlon e Denigés Origiginal e modificado foi usado - caldo infuso de coração de boi ${ }^{14} *$ e nos testes com Zefirol, Sterylderme e Germekil foi utilizado o meio desidratado Bacto Brain Heart Infusion.

2.3.1.2. Em cada um dos cultivos colocar cones de papel absorvente esterilizados fazendo os mes-

\footnotetext{
* Coração de Boi $500 \mathrm{~g}$ Polipeptona $\quad 10 \mathrm{~g}$ Cloreto de sódio $\quad 5 \mathrm{~g}$ Água destilada $1000 \mathrm{ml}$
} 
mos aí permanecerem $p$ elo tempo d e 2 (dois) minutos.

2.3.1.3. Com uma pinça flambada e técnica asséptica imergir as pontas em uma placa de Petri contendo o antissético a testar, aí permanecendo por 1 , $2,5,10,20 \mathrm{e}$ 30 minutos. Após transportar as pontas para tubos com meio de cultura estéril e levar a estufa a $37^{\circ} \mathrm{C}$.

2.3.1.4. Como contrôle utilizar cone de papel absorvente contaminado na cultura, transferido de u m a p a a de Petri para um tubo com meio de cultivo estéril.

2.3.1.5. Leitura dos resultados através da turvação do meio após 24, 48 e 72 horas.
2.3.2. Método com coquetel bacteriano (Quadro II) 2.3.2.1. Cultivar separadamente o $B$. subtilis, S. aureus, $K$. pneumoniae, $S$. typhosa, P. vulgaris, $\mathrm{S}$. marcescem, E. coli e B. anthracis.

2.3.2.2. Após 24 horas transferir $1 \mathrm{ml}$ de cultura de c a d a amostra para um tubo de ensaio.

2.3.2.3. No coquetel colocar cones de papel absorvente esterilizados fazendo os mesmos aí permanecerem pelo t e m po de 2 (dois) minutos. A partir daqui como no método anterior em 2.3.1.3. e .... 2.3.1.4. e ... 2.3.1.5.

2.3.3. Método com material radicular (Quadro III)

2.3.3.1. O material de canal foi recolhido de dentes de p a c ientes em tratamento endodôntico na Clínica Integrada. 
2.3.4.2. Com uma pinça flambada introduzir no canal radicular, per' feitamente isolado, um cone de papel absorvente esterilizado fazendo o mesmo aí permanecer por dois minutos.

2,3.4.3. Com pinça flambada transferir o cone para um tubo com meio de cultura e levar à estufa a $37^{\circ} \mathrm{C}$ por 24 horas. No cultivo de canal de 24 horas colocar pontas de papel absorvente esterilizadas fazendo os mesmos aí permanecerem pelo tempo de dois minutos.

A partir daqui como no ..... 2.3.1.3., $\ldots .$. 2.3.1.4. e W. 2.3.1.5. no método de microrganismos isolados.

2.3.4. Método com estreptoco$\cos$ (Quadro IV)

2.3.4.1. O material de canal foi reco- lhido de dentes de pacientes em tratamento endodônt i c o na Clínica integrada.

2.3.4.2. Com uma pinça flambada introduzir no canal radicular, perfeitamente isolado, um cone de papel absorvente esterilizado fazendo $o$ mesmo aí permanecer por dois minutos.

2.3.4.3. Com pinç a flambada transferir o cone para um tubo com meio de cultura e levar à estufa a $37^{\circ} \mathrm{C}$ por 24 horas.

2.3.4.4. Com o auxílio de uma alça de platina transferir o cultivo de 24 horas para uma placa de a gar cérebro coração e levar à estufa a $37^{\circ} \mathrm{C}$ por 24 horas.

2.3.4.5. As colônias isoladas que após esfregaço e color a @ ão de Gram apresentaram cocos Gram positivos foram reisola- 
das em placas

de agar cérebro

coração.

2.3.4.6. No cultivo de

24 horas colocar pontas de papel absorventes esterilizadas fazendo as mesmas aí permanecerem pelo tempo de dois minutos. A partir daqui como no 2.3.1.3., .. 2.3.1.4. e ... 2.3.1.5.

De cada método e para cada antisséptico realizamos no mínimo dois testes, chegando às vêzes a oito.

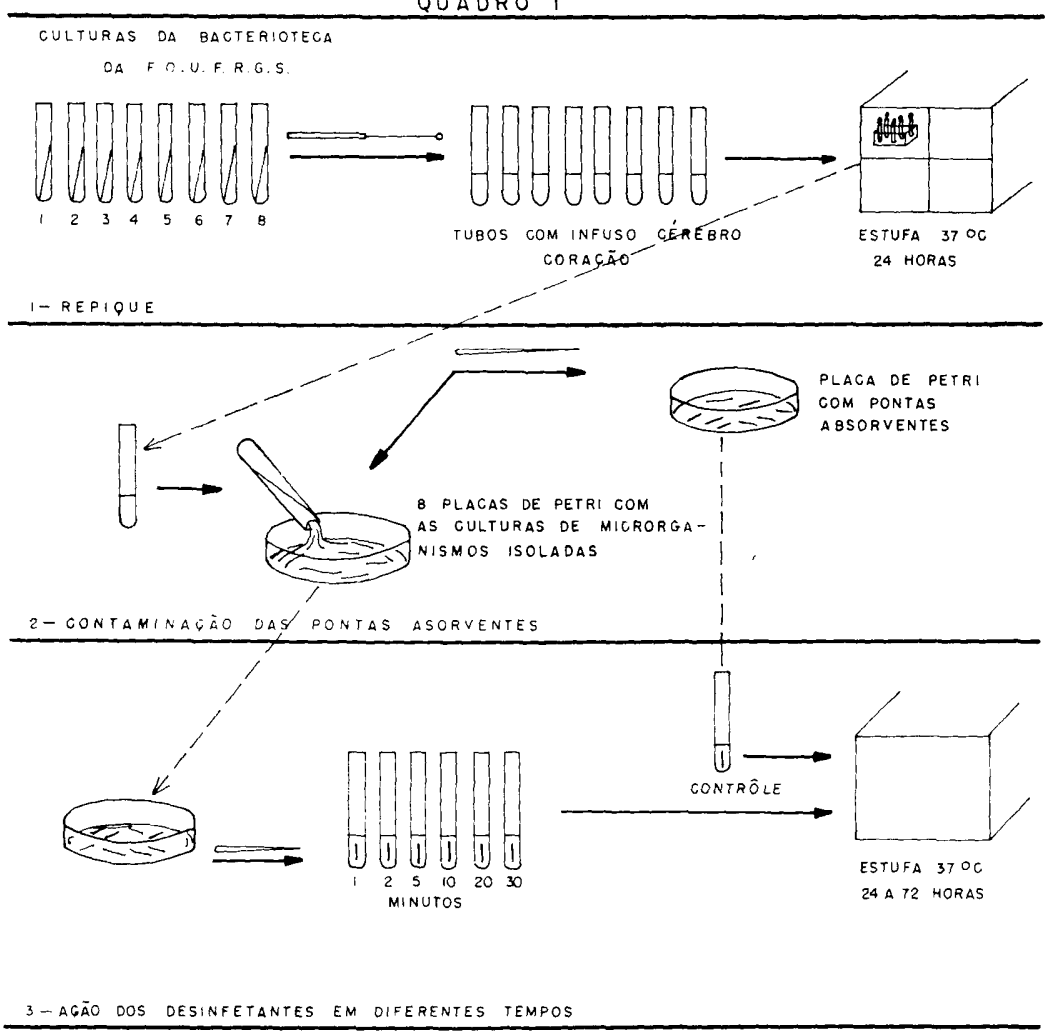

R. Fac. Odont. P. A. 


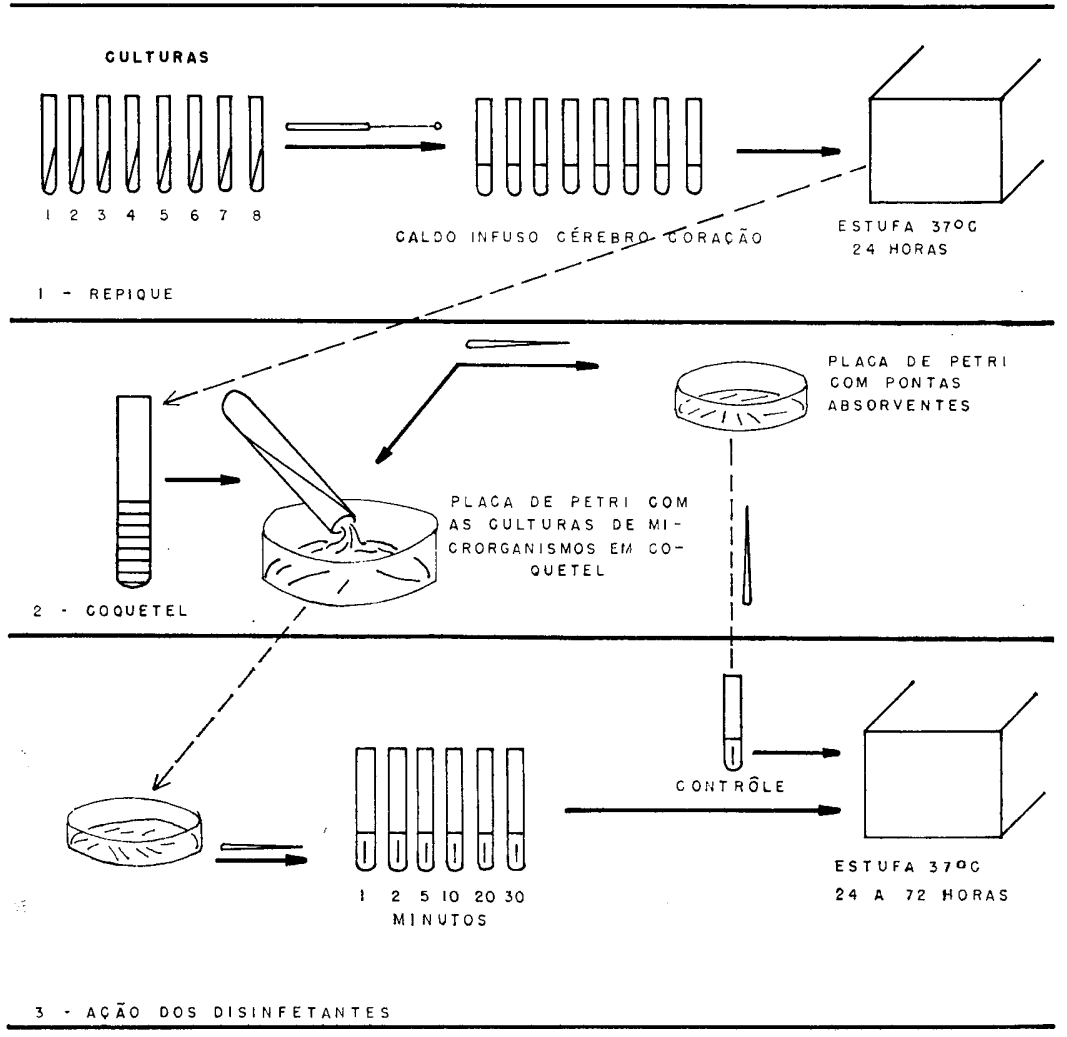

R. Fac. Odont. P. A. 
QUADRO 111

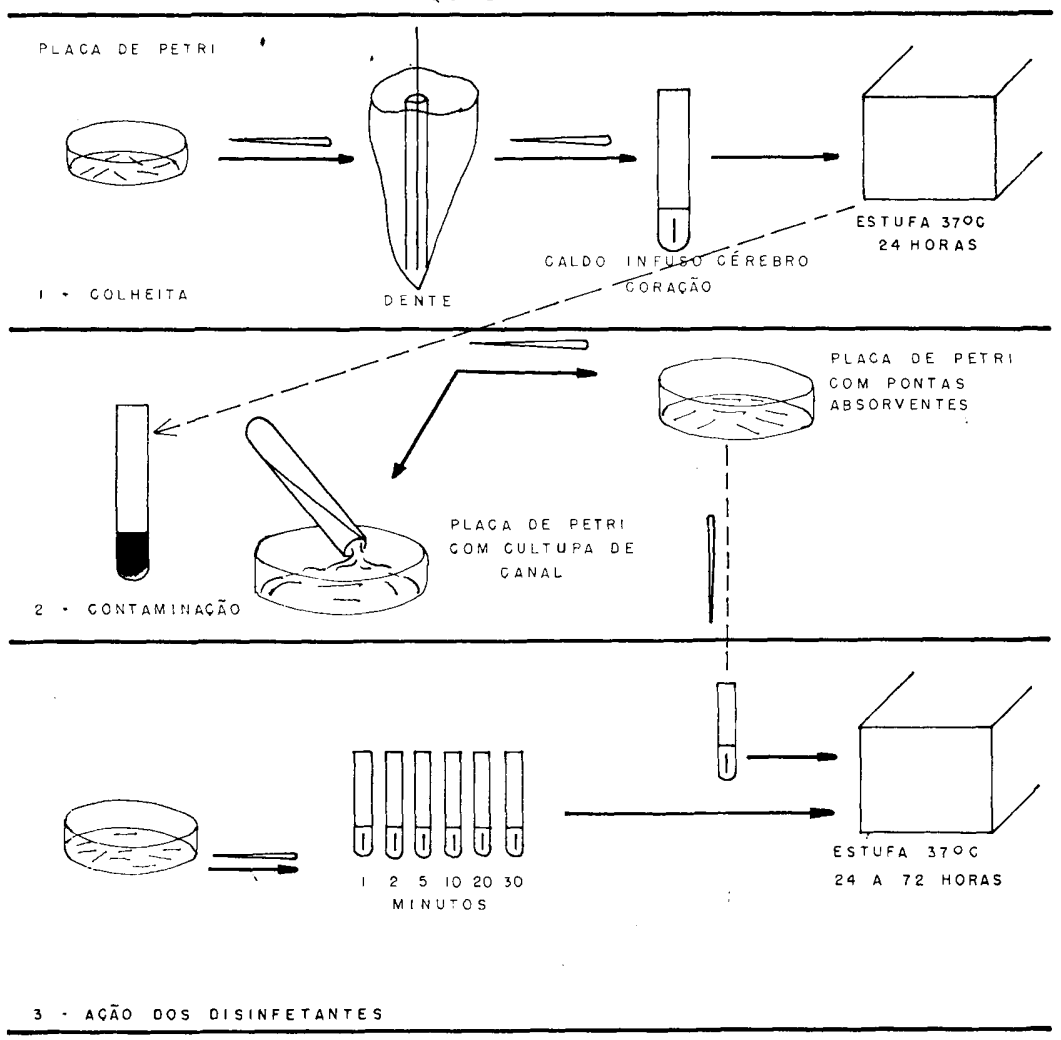

R. Fac. Odont. P. A. 
QUADRO IV
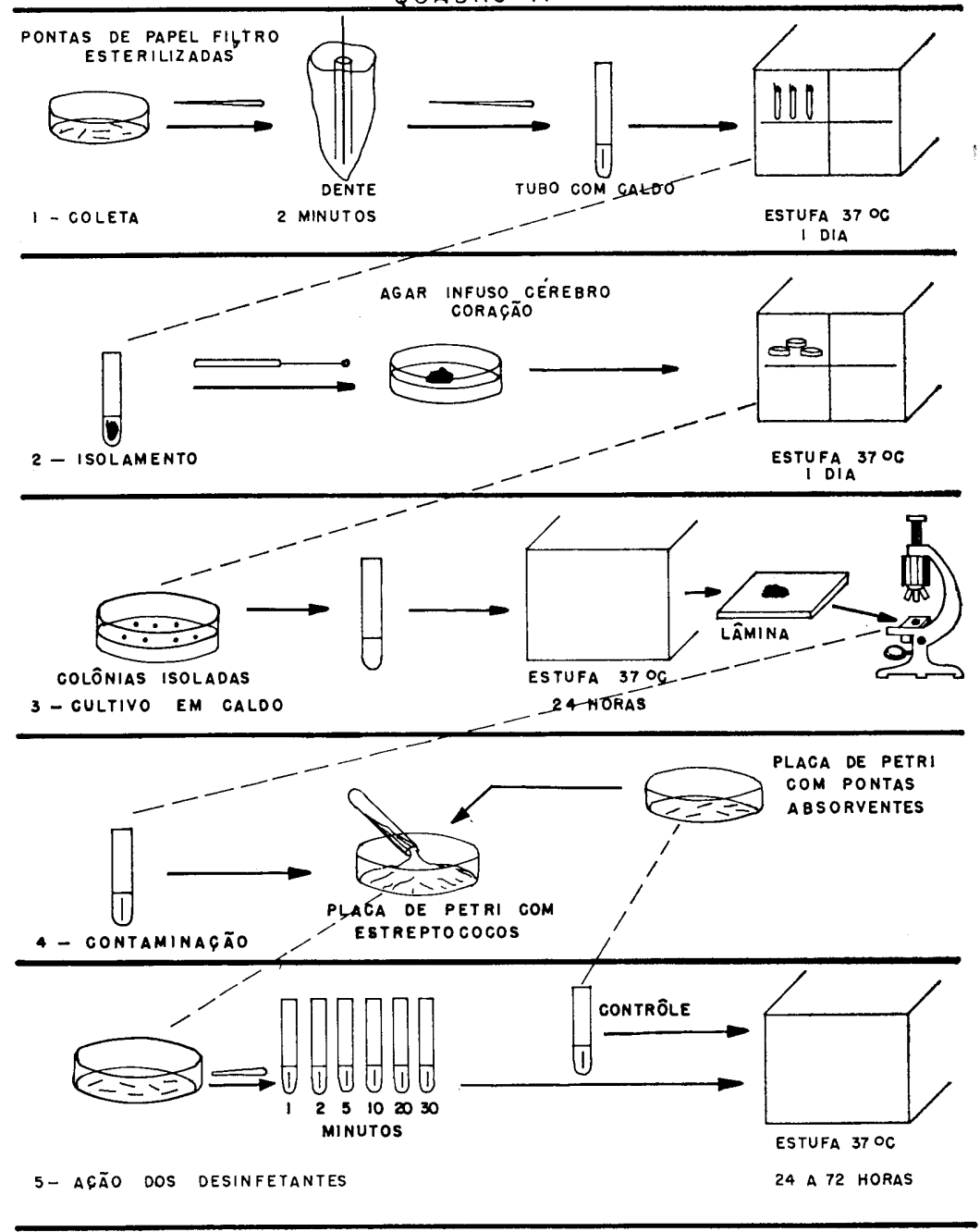

R. Fac. Odont. P. A. 


\section{3 - RESULTADOS}

Os resultados da atuação dos diferentes agentes químicos antimicrobianos são apresentados nos quadros I, II, III, IV, V e VI.
Cada quadro mostra os resultados de no mínimo duas experiências e no máximo oito frente aos diferentes microrganismos, , coquetel bacteriano e microrganismos de canal radicular.

\section{QUADRO I}

RESULTADOS APRESENTADOS PELO DESINFETANTE ZFEFIROL EM DIFERENTES TEMPOS DE EXPOSIÇÃO COM DIFERENTES - MICRORGANISMOS

TEMPOS DE EXPOSIÇÃO (MINUTOS)

\begin{tabular}{|c|c|c|c|c|c|c|c|}
\hline MICRORGANISMOS & 1 & 2 & 5 & 10 & 20 & 30 & CONT. \\
\hline B. subtilis & - & - & - & - & - & - & $\mathrm{x}$ \\
\hline St. aureus & - & - & - & - & - & - & $\mathrm{x}$ \\
\hline K. pneumoniae & - & - & - & - & - & - & $\mathrm{x}$ \\
\hline S. typhosa & $\mathrm{x}$ & $\mathrm{x}$ & $\mathrm{x}$ & $\mathrm{x}$ & $\mathrm{x}$ & $\mathrm{x}$ & $\mathrm{x}$ \\
\hline P. vulgaris & $\mathrm{x}$ & $\mathrm{x}$ & $\mathrm{x}$ & $\mathrm{x}$ & $\mathrm{x}$ & $\mathrm{X}$ & $\mathrm{x}$ \\
\hline S. marcescens & $\mathrm{x}$ & $\mathrm{x}$ & $\mathrm{x}$ & $\mathrm{x}$ & $\mathrm{x}$ & $\mathrm{X}$ & $\mathrm{x}$ \\
\hline E. Coli & $\mathrm{x}$ & $\mathrm{x}$ & $\mathrm{x}$ & $\mathrm{x}$ & $\mathrm{x}$ & $\mathrm{x}$ & $\mathrm{x}$ \\
\hline B. anthracis & - & 一 & - & - & - & - & $\mathrm{x}$ \\
\hline Estreptococos de canal & 一 & - & - & - & - & - & $\mathrm{x}$ \\
\hline Cultura de canal & - & - & - & 一 & - & - & $\mathrm{x}$ \\
\hline Coquetel & $\mathrm{x}$ & $\mathrm{x}$ & $\mathrm{x}$ & $\mathrm{x}$ & $\mathrm{x}$ & $\mathrm{x}$ & $\mathrm{x}$ \\
\hline
\end{tabular}

$$
\begin{aligned}
& \mathrm{X}=\text { crescimento } \\
& -\mathrm{Z}=\text { ausência de crescimento }
\end{aligned}
$$

R. Fac. Odont. P. A. 


\section{QUADRO II}

RESULTADOS APRESENTADOS PELO DESINFETANTE STERYLDERME EM DIFERENTES TEMPOS DE EXPOSIÇÃO COM DIFERENTES MICRORGANISMOS

TEMPOS DE EXPOSIÇÃO (MINUTOS)

\begin{tabular}{|c|c|c|c|c|c|c|c|}
\hline MICRORGANISMOS & 1 & 2 & 5 & 10 & 20 & 30 & CONT. \\
\hline B. subtilis & - & - & 一 & - & - & - & $\mathrm{X}$ \\
\hline St. aureus & - & 一 & - & - & - & - & $\mathrm{x}$ \\
\hline K. pneumoniae & - & - & - & - & - & - & $\mathrm{x}$ \\
\hline S. typhosa & - & 一 & - & - & $\longrightarrow$ & - & $\mathrm{x}$ \\
\hline P. vulgaris & - & 一 & - & 一 & - & - & $\mathrm{X}$ \\
\hline S. marcescens & - & - & - & - & - & - & $\mathrm{x}$ \\
\hline E. Coli & - & 一 & - & - & - & - & $\mathrm{x}$ \\
\hline B. anthracis & - & - & - & - & 一 & - & $\mathbf{x}$ \\
\hline Estreptococos de canal & - & - & - & - & - & - & $\mathrm{x}$ \\
\hline Cultura de canal & - & 一 & - & 一 & - & - & $\mathrm{x}$ \\
\hline Coquetel & 一 & 一 & - & - & 一 & 一 & $\mathrm{X}$ \\
\hline
\end{tabular}

$\mathrm{X}=$ crescimento

- = ausência de crescimento

R. Fac. Oơont. P. A.

10/11: 83-103, $1968 / 1969$ 


\section{QUADRO III}

RESULTADOS PELO DESINFETANTE DENIGFS MODIEICADO EM DIFERENTES TEMPOS DE EXPOSTÇÃO COM DIFERENTES MICRORGANISMOS

TEMPOS DE EXPOSIÇÃO (MINUTOS)

MICRORGAN'ISMOS .

B. subtilis

St. aureus

K. pneumoniae

S. typhosa

P. vulgaris

S. marcescens

E. Coli

B. anthracis

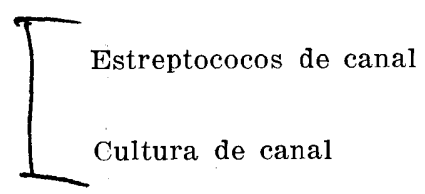

Coquetel

\section{TEMPOS DE EXPOSICAO (MINUTOS)}

\begin{tabular}{|l|l|l|l|l|}
\hline & & & & \\
\hline
\end{tabular}

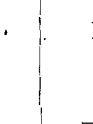

1

(




\section{QUADRO IV}

RESULTADOS APRESENTADOS PELO DESINFETANTE DENIGES ORIGINAL EM DIFERENTES TEMPOS DE EXPOSIÇÃO COM DIFERENTES MICRORGANISMOS

TEMPOS DE EXPOSIÇÃO (MINUTOS)

\begin{tabular}{|c|c|c|c|c|c|c|c|}
\hline MICRORGANISMOS & 1 & 2 & 5 & 10 & 20 & 30 & CONT. \\
\hline B. subtilis & - & - & - & - & - & - & $x$ \\
\hline St. aureus & - & - & - & - & - & - & $\mathrm{x}$ \\
\hline K. pneumoniae & - & - & - & - & - & - & $\mathrm{x}$ \\
\hline s. typhosa & 一 & - & - & - & - & - & $x$ \\
\hline P. vulgaris & 一 & - & - & - & - & - & $\mathrm{x}$ \\
\hline s. marcescens & - & 一 & 一 & 一 & - & - & $\mathrm{x}$ \\
\hline E. Coli & - & 一 & - & 一 & 一 & - & $\mathrm{x}$ \\
\hline B. anthracis & - & 一 & 一 & 一 & 一 & - & $\mathrm{X}$ \\
\hline Estreptococos de canal & $\mathrm{X}$ & $\mathrm{X}$ & $\mathrm{x}$ & $\mathrm{x}$ & $\mathrm{x}$ & $\mathrm{x}$ & $\mathrm{x}$ \\
\hline $\begin{array}{c}\text { Cultura de canal } \\
:=\end{array}$ & $\mathrm{x}$ & $\mathrm{x}$ & $\mathrm{x}$ & $\mathrm{x}$ & $\mathrm{x}$ & $\mathrm{x}$ & $\mathrm{x}$ \\
\hline Coquetel & - & - & 一 & - & 一 & - & $\mathrm{x}$ \\
\hline
\end{tabular}

$\mathrm{X}=$ crescimento

- = ausência de crescimento

R. Fac. Odort. P. A. 


\section{QUADRO V}

RESULTADOS APRESENTADOS PELO DESINFETANTE GERMEKIL EM DIFERENTES TEMPOS DE EXPOSIÇÃO COM DIFERENTES

MICRORGANISMOS

TEMPOS DE EXPOSIÇÃO (MINUTOS)

\begin{tabular}{|c|c|c|c|c|c|c|c|}
\hline MICRORGANISMOS, & 1 & 2 & 5 & 10 & 20 & 30 & CONT \\
\hline B. subtilis & 一 & - & 一 & - & - & - & $\mathrm{x}$ \\
\hline St. aureus & - & - & - & - & - & - & $\mathrm{x}$ \\
\hline K. pneumoniae & $\mathrm{X}$ & - & - & - & 一 & - & $x$ \\
\hline S. typhosa & - & - & - & - & - & - & $\mathrm{x}$ \\
\hline P. vulgaris & $\mathrm{x}$ & - & - & - & - & - & $\mathrm{X}$ \\
\hline S. marcescens & $\mathrm{X}$ & - & 一 & - & - & - & $\mathrm{x}$ \\
\hline E. Coli & $\mathrm{x}$ & - & - & - & - & - & $\mathrm{X}$ \\
\hline \multicolumn{8}{|l|}{ B. anthracis * } \\
\hline Estreptococos de canal & - & - & - & - & - & - & $\mathrm{x}$ \\
\hline Cultura de canal - & - & 一 & - & - & - & - & $\mathrm{x}$ \\
\hline Coquetel $*$ & & & & & & & \\
\hline
\end{tabular}

$$
\begin{aligned}
\mathrm{X} & =\text { crescimento } \\
- & =\text { ausência de crescimento } \\
* & =\text { testes não realizados }
\end{aligned}
$$

R. Fac. Odont. P. A. 


\section{QUADRO VI}

RESLlTADOS APRESENTADOS PELO DESINFETANTE CETAVLON EM DIFERENTES TEMPOS DE EXPOSIÇÃO COM DIFERENTES

MICRORGANISMOS

TEMPOS DE EXPOSIÇÃO (MINUTOS)

\begin{tabular}{|c|c|c|c|c|c|c|c|}
\hline MICRORGANISMOS & 1 & 2 & 5 & 10 & 20 & 30 & CONT \\
\hline B. subtilis & - & - & - & - & - & - & $\mathrm{x}$ \\
\hline St. aureus & - & - & - & - & - & - & $\mathrm{x}$ \\
\hline K. pneumoniae & $\mathrm{x}$ & $\mathrm{x}$ & $\mathrm{x}$ & $\mathrm{x}$ & $\mathrm{x}$ & $\mathrm{x}$ & $\mathrm{x}$ \\
\hline s. typhosa & $\mathrm{x}$ & $\mathrm{x}$ & $\mathrm{x}$ & $\mathrm{x}$ & $\mathrm{x}$ & $\mathrm{x}$ & $\mathrm{x}$ \\
\hline P. vulgaris & $\mathrm{x}$ & $\mathrm{x}$ & $\mathrm{x}$ & $\mathrm{x}$ & $\mathrm{x}$ & $\mathrm{x}$ & $\mathrm{x}$ \\
\hline S. marcescens & $\mathrm{x}$ & $\mathrm{x}$ & $\mathrm{x}$ & $\mathrm{x}$ & $\mathrm{x}$ & $\mathrm{x}$ & $\mathrm{x}$ \\
\hline E. Coli & $\mathrm{x}$ & $\mathrm{x}$ & $\mathrm{x}$ & $\mathrm{x}$ & $\mathrm{x}$ & $\mathrm{x}$ & $\mathrm{x}$ \\
\hline B. anthracis & - & - & - & - & - & - & $\mathrm{x}$ \\
\hline Estreptococos de canal & - & - & - & - & - & - & $\mathrm{x}$ \\
\hline Cultura de canal & - & - & - & 一 & - & - & $\mathrm{x}$ \\
\hline Coquetel & $\mathrm{x}$ & $\mathrm{x}$ & $\mathrm{x}$ & $\mathrm{x}$ & $\mathrm{x}$ & $\mathrm{x}$ & $\mathrm{x}$ \\
\hline
\end{tabular}

$\mathrm{X}=$ crescimento

- = ausência de crescimento

R. Fac. Odont. P. A.

10/11: $83-103,1968 / 1969$ 


\section{4 - DISCUSSÃO}

Portellada 22 publicou um trabalho mostrando que Badan nas três edicões de seu livro Oxigenoargentoterapia $2,3,4$, havia transcrito a fórmula do Líquido de Denigés, encontrada na primeira edição de Richaud ${ }^{23}$, que no entanto "estava errada, tanto assim que já na segunda ${ }^{24}$ e nas outras edicões Richaud traz a fórmula correta, isto é, cianeto de mercúrio no lugar de cianeto de potássio. Em nosso trabalho não utilizamos a fórmula de Badan1,2,3 pela comprovada ineficiência do cianeto de potássio como agente de desinfecção e esterilização.

o líquido de Denigés tanto a fórmula original como a modificada, mostrou ter uma ação esterilizante frente a Salmonella typhosa não só em 5 minutos como relatou Portella$\mathrm{da}^{22}$ mas em 1, 2, 5, 10, 20 e 30 minutos. Este resultado veio confirmar os achados de Portellada22 e contrariar Lima e Tabacof ${ }^{12}$ que mostraram que em 5 minutos havia crescimento de microrganismos.

Os resultados por nós obtidos com o Líquido de Denigés tanto na fórmula original como na modificada vieram a confirmar os trabalhos de Tovo ${ }^{26}$ frente a um coquetel de microrganismos, pois não houve crescimento desde 1 minuto até 30 minutos.

Os resultados obtidos por Lima e Tabacof ${ }^{12}$ realmente não poderiam confirmar os de Tovo pois ambos trabalharam com cepas de microrganismos diferentes.

Sales Cunha 7 através de um artigo intitulado de «Ato Falhado» procurou defender Mário Badan, da afirmação de um estudante, de que a fórmula empregada por seu assistente não tinha a minima ação antisséptica. Acreditamos que Badan tenha utilizado em seus trabalhos a fórmula errada, devido à citação que o mesmo faz, da $1^{a}$ edição do livro de Richaud 1908, cuja fórmula já falamos encontrar-se errada na referida edição.

Sales Cunha na ânsia de defender seu assistente não se deu conta de que Badan transcreveu a fórmula da $1^{a}$ edição de Richaud (1908) que estava errada e que a bibliografia citada por êle é a da $2^{a}$ edição 1914, já corrigida.

Discordamos de Milano ${ }^{26}$ quando diz que Tovo testou o Líquido de Denigés, fórmula de Badan, pois a fórmula apresentada no trabalho é a do Líquido de Denigés modificada por Portellada22.

Os nossos resultados permitem confirmar os achados de Madureira ${ }^{16}$ referente à ação do Cetavlon frente aos bacilos esporulados (B. subtilis e B. anthracis) pois o mesmo se mostrou eficiente para ambos os microrganismos.

o Cetavlon não se mostrou igualmente eficiente frente ao coquetel bacteriano, o mesmo utilizado por Tovo ${ }^{26}$, pois houve crescimento em todos os tempos de exposição, o que confirma também a ineficiência do Cetavlon ante o coquetel descrito.

A observação dos resultados permite-nos discordar de Grosmann11 quando diz que o «Zefirol não tem ação sôbre os microrganismos esporulađos» pois verificamos a sua ação frente aos B. subtilis e B. anthracis.

Cumpre salientar que a patente do Sterylderme por nós utilizada foi ad- 
quirida pelo Laboratório Darrow $\mathrm{S}$. A que passou a denominar êste produto de Germekil.

Im fato que nos chamou a atenção é que o Germekil frente a $\mathrm{K}$. pneumoniae, $P$. vulgaris, $S$. marcescens e E. coli no tempo de 1 minuto não mostrou ação esterilizante como aconteceu com o Sterylderme que foi esterilizante em todos os tempos.

Isto, provàvelmente pode ser decorrência de uma ligeira modificação na constituição do produto, ou de outro fator desconhecido, o que poderá servir de objeto para futuras investigações.

Germekil não foi testado frente ao B. anthracis por havermos perdido a amostra e que nos impossibilitou igualmente de testá-lo frente ao coquetel de microrganismos.

\section{5) CONCLUSõES}

Da análise dos quadros, cujo discussão realizamos anteriormente, acreditamos seja lícito chegar as seguintes conclusões:

1 - 0 Denigès Fórmula Original e fórmula modificada por Portellada não são indicados para a esterilização do instrumental endodêntico por não atuarem sôbre cultivos de microrganismos de canal e estreptococos

2 - o Cetavlon e o Zefirol mostraram não ter ação sôbre uma série de microrganismos da bacterioteca da F.O.U.F.R.G.S., mas atua ram contra os microrganismos de canal radicular e estreptococos isolados dos mesmos o que nos leva a considerá-los como bons desinfetantes.

3 - o Germekil mostrou eficiência contra todos os microrganismos da basterioteca (exceção ao P. vulgaris, $\mathrm{K}$, pneumoniae e $\mathrm{S}$. marcescens, no tempo de 1 minuto), contra os microrganismos de canal e estreptococos isolados do mesmo.

o sterylderme mostrou eficiência contra todos os microrganismos da bacterioteca, contra cultivos de microrganismos de canal radicular e estreptococos isolados de canal radicular, o que nos leva a considerá-los como ótimos desinfetantes.

\section{SYNOPSIS}

Desinfectant action of some chemical agents of dentistry use were tested to known microrganisms and to root canal cultures. 


\section{REFERÊYCIAS BIBLIOGRÁFICAS}

1. AMERICAN DENTAL ASSOCIATION. Remédios dentários oficiais. 27.ed. Centro de publicação da aliança Missão Norte-americana de Cooperação Técnica no Brasil. Rio de Janeiro, USAID, 1962. p. 116.

2. BADAN, Mário. Oxigenoargentoterapia. São Paulo, Científica, 1949. p. 116.

3. BADAN, Mário, Oxigenoargentoterapia. 2.ed. Rio de Janeiro, Científica, 1952.

4. BADAN, Mário. Oxigenoargentoterapia. 3.ed. Rio de Janeiro, Científica, 1956. p. 59.

5. CAUdURO, Haroldo. Manual de endodontia. Pôrto Alegre, Revista Gaúcha de Odontologia, 1964, p. 30.

6. COOLIDGE, Edgar D. \& KESEL, Robert G. Endodontologia. Buenos Aires, Editorial Bibliográfica Argentina, 1957. p. 207.

7. CUNHA, Sales M. Ato falhado. Revista de Farmácia e Odontologia, Niterói, 1962. p. 255.

8. FIlgueiras, Jayme et alii. Endodontia clínica. Rio de Janeiro, Científica, 1962. p. 64.

9. FIlGUeiras, Jayme \& MELLO, Cláudio F. Patologia da polpa dentária. 3.ed. Rio de Janeiro, Científica, 1955. p. 115.

10. Filgueiras, Jayme \& MELLo, Cláudio F. Patologia da polpa dentária. 2.ed. Rio de Janeiro, Científica, 1947. p. 175.

11. GROSSMAN, Louis T. Tratamento dos canais radiculares. 2.ed. Rio de Janeiro, Atheneu, 1956. p. 261.

12. LIMA, J. O. \& TABACOF - Desinfecção do instrumental em dentisteria; líquido de Denigès e bromêto de cetiltrimetilamônio. Revista da Associação Paulista de Cirurgiões Dentistas, São Paulo, 18:133, 1964.

13. INSTITUTO TECNOLóGICO DO RIO GRANDE DO SUL. Relatório 2105 à Química «BAYER». Pôrto Alegre, 1962.

14. LOURo $\mathrm{F}^{\circ}$, Paulo $\mathrm{P}$. Contribuição ao estudo dos estreptococos em bôlsas fisiológicas e patológicas gengivais. Pôrto Alegre, Globo, 1957, p. 22. Tese.

15. LABORATóRIO DARROW. Moderna assepsia hospitalar para combater as infecções cruzadas, divisão de antissépticos, 1955. p. 11.

16. MADUREIRA, Nelson. Esterilização química pelo bromêto de cetiltrimetilamônio. Revista Gaúcha de Odontologia, Pôrto Alegre, $8: 205,1960$.

17. MADUREIRA, Nelson. Esterilização dos fluídos e peças empregadas na alta rotação. Revista Gaúcha de Odontologia, Pôrto Alegre, $37,1961$. 
18. MaDLREIRA, Nelson. Esterilização rápida dos instrumentos endodônticos. Revista Gaúcha de Odontologia, Pôrto Alegre, 8:206; 1960.

19. MadtREIRA, Nelson. Esterilização mista. Revista Gaúcha de Odontologia, Pôrto Alegre, 8:206, 1960.

7ị. MaRcos PRoDUtos QUímicos. Dados técnicos; princípio ativo do Sterylderme. Rio de Janeiro.

21. MORSE, F. W. Follow studies of root filled teeth relation bacteriologie findig. Journal Studies of American Dental Association, Chicago, 28:956-971, 1941.

22. PORTELladA, Pio. Retificação da fórmula de líquido de Denigés (liquido de Badan). Revista Odontologia, Rio de Janeiro, 36:3, 1960.

¿3. RICHAUD, A. Precie de therapeutique et pharmacologie. Paris, Masson e Cia. Editeurs, 1908. p. 116.

24. RICHAUD, A. Precie de therapeutique et pharmacologie. 2. ed. Paris, Masson e Cia. Editeurs, 1911. p. 112.

25. SOMMER, Ralph et alii. Endodoncia clínica. Buenos Aires, Mundi, 1958. p. 519.

26. TOVO, Luiz C. \& MILANO, Nicolau Fonseca. Considerações em tôrno do emprêgo do Cetavlon e do líquido de Denigès. Revista Gaúcha de Odontologia, Pôrto Alegre, 10:133, 1962.

27. Tovo, Luiz C. Comunicação pessoal.

28. WINCLER, K. C. \& VON AMERONGEN, J. Resultados bacteriológi$\cos$ de 4.000 culturas de canais. Oral Surgery, Oral Medicine and Oral Phatology, St. Louis, 12:857-875, 1959. 